\title{
Madera y Bosques \\ Anatomía de la hoja de seis especies de Pinus del estado de Durango, México
}

\section{Anatomy of leaves of six Pinus species from the state of Durango, México}

\author{
Carmen de la Paz Pérez Olvera' y Jacqueline Ceja-Romero²
}

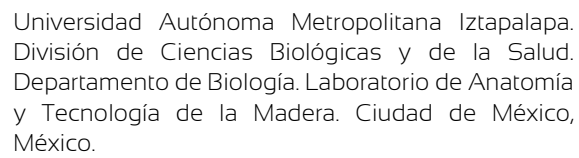

Universidad Autónoma Metropolitana Iztapalapa. División de Ciencias Biológicas y de la Salud. Departamento de Biología. Laboratorio de Anatomía y Tecnología de la Madera. Ciudad de México, México.

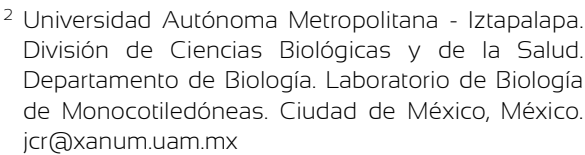

* Autora de correspondencia. cppo@xanum.uam.mx

\section{RESUMEN}

México es el país con mayor número de especies de Pinus en el mundo con alrededor de 49, de las cuales, se tienen registradas 20 para el estado de Durango. A pesar de ser el género más utilizado como maderable, es poca la información que se tiene sobre las características de sus hojas. Los estudios sobre la anatomía foliar de Pinus, han mostrado que algunas características son útiles para su clasificación, por lo que en este trabajo se presenta la descripción morfológica y anatómica de la hoja de seis especies recolectadas en dos municipios del estado de Durango, con el fin de determinar si hay diferencias entre ellas que puedan ser útiles en este sentido. Las muestras se obtuvieron a partir de material herborizado que fue hidratado y procesado a través de la técnica de inclusión en parafina, para la obtención de preparaciones permanentes. Los caracteres morfológicos estudiados fueron: presencia-ausencia, color y longitud de la vaina, margen, longitud y diámetro de la acícula, número de acículas por fascículo. Los anatómicos fueron: forma de la hoja en corte transversal, cantidad de hileras de estomas en vista superficial y características de la epidermis, mesófilo y sistema vascular. Pinus leiophylla fue la única especie con vaina decidua, si bien en todas las especies la forma de la lámina en corte transversal fue triangular, se registró variación en la apertura de los ángulos y en la posición de los canales resiníferos, sin embargo, no se observan diferencias entre los representantes de las subsecciones Ponderosae y Australes, que pudieran tener utilidad taxonómica.

PALABRAS ClAVE: acículas, anatomía foliar, morfología, Pinaceae, sección Trifoliae

\section{ABSTRACT}

México is the country with the highest number of Pinus species in the world, with around 49, of which in Durango there are registered 20. Despite being the genus most used as timber, the information about its leaf characteristics is scarce. Studies about foliar anatomy of Pinus, have shown that some features are useful for their classification, therefore in this paper the morphological and anatomical description of the leaves of six species collected in two municipalities in the state of Durango is presented, in order to determine if there are differences between them that may be useful in this sense. Samples were obtained from herborized material, which was hydrated and processed through the paraffin embedding protocol, to obtain permanent slides. The morphological characters studied were: presenceabsence, color and length of the sheath; margin, length and diameter of the needles, number of needles per fascicle. The anatomical characters were: shape of the leaf in cross section, number of stomata rows in superficial view and characteristics of epidermis, mesophyll and vascular system. P. leiophyla was the only species with deciduous sheath. Although in all taxa the shape of the leaf was triangular in cross section, there was variation in the opening of the angles and the position on the resin ducts, however no differences were observed between the representatives of the Ponderosae and Australes subsections, which may have taxonomic utility.

KEYWORDS: needles, leaf anatomy, morphology, Pinaceae, section Trifoliae 


\section{INTRODUCCIÓN}

El origen de las Coníferas, grupo al que pertenece el género Pinus, se remonta al Carbonífero superior, hace aproximadamente unos 290 millones de años, el grupo alcanzó su esplendor en el Triásico, hace 248 millones de años (Bold, Alexopoulus, Delevoryas, 1980; Cevallos y Calvillo, 2012), en condiciones climáticas extremas de sequía y frío (Bold et al., 1980; Raven, Everty y Eichhorn, 2004).

Entre los géneros de coníferas que habitan en México, el de mayor riqueza específica es Pinus, con 49 (40\%) de las aproximadamente 120 especies que hay en el mundo (Gernandt y Pérez-de la Rosa, 2014). Los bosques de Pinus, son uno de los elementos dominantes de la vegetación actual, su distribución coincide con los elevados macizos montañosos y están presentes en todas las entidades federativas del país con excepción de Yucatán (Martínez, 1948; Rzedowski, 1978; Gernandt y Pérez de la Rosa, 2014). La morfología y disposición de sus hojas les confiere una fisonomía particular que hace que difícilmente se confundan con otro tipo de vegetación, la mayoría de sus especies tienen valor comercial y son importantes tanto en la producción maderable como en la no maderable (Rzedowski, 1978; Instituto Nacional de Estadística y Geografía [Inegi], 2014).

El estado de Durango, México, tiene una superficie forestal de 4.98 millones de hectáreas, con una existencia maderable de $422 \times 10^{6} \mathrm{~m}^{3}$ entre bosques de latifoliadas y de coníferas (Inegi, 2014). De las 20 especies de Pinus que se tiene registradas para esta entidad, destacan por su valor comercial: $P$. ayacabuite Ehrenb ex Schtld., P. arizonica Engelm., P. cooperi C. E. Blanco, P. durangensis Martínez, P. engelmannii Carrière y P. teocote Schide. ex Schltdl. \& Cham. (García y González-Elizondo, 2003), cuatro de ellas se incluyen en este trabajo.

Se ha documentado que el estudio de características anatómicas de las hojas del género Pinus, tales como: número de haces vasculares, posición de los conductos resiníferos, distribución de los estomas y forma de la lámina en corte transversal, proporcionan información que puede ser útil en la clasificación e identificación de las especies que lo conforman, por lo que se señala la necesidad de trabajar en el tema (Esau, 1972; Foster y Gifford, 1974; Bold et al., 1980; Burzo, Toma, Mihăescu y Toma., 2004; Dörken y Stützel, 2012; Ghimire, Lee, Yang y Heo, 2015).

\section{OBJETIVOS}

Describir las características morfológicas y microscópicas de las hojas de Pinus arizonica, P. cooperi, P. durangensis, $P$. herrerae, P. leiophylla y P. teocote, especies del subgénero Pinus, sección Trifoliae, recolectadas en bosques de pino-encino de los municipios de Santiago Papasquiaro y Durango, en el estado de Durango, México, con el fin de aportar datos que permitan ampliar el conocimiento de las mismas.

\section{MATERIALES Y MÉTODOS}

El material de estudio se obtuvo a partir de ejemplares depositados en el Herbario Metropolitano Ramón Riva y Nava de la UAM Iztapalapa, que fueron recolectados en bosques de pino-encino en los municipios de Santiago Papasquiaro y Durango, en el estado de Durango, a una altitud entre 2604 m y 2727 m snm (Tabla 1). Mayores detalles de los sitios de recolección se presentan en De la Paz Pérez y Dávalos-Sotelo (2016).

TABla 1. Datos de recolección de las especies de Pinus estudiadas

\begin{tabular}{llccccc}
\hline Especies & Sección & Subsección & Municipio & Altitud & No. de herbario & Colector \\
\hline Pinus arizonica & Trifoliae & Ponderosae & Santiago Papasquiaro & 2605 & 79498 & Abel García \\
P. cooperi & Trifoliae & Ponderosae & Durango & 2727 & 79509 & Abel García \\
P. durangensis & Trifoliae & Ponderosae & Santiago Papasquiaro & 2606 & 79505 & Abel García \\
P. herrerae & Trifoliae & Australes & Santiago Papasquiaro & 2608 & 79503 & Abel García \\
P. leiophylla & Trifoliae & Australes & Santiago Papasquiaro & 2604 & 79501 & Abel García \\
P. teocote & Trifoliae & Australes & Durango & 2723 & 79500 & Abel García \\
\hline
\end{tabular}


De cada ejemplar de herbario se seleccionaron 20 acículas maduras a partir de las cuales se obtuvieron los datos morfológicos. Para la descripción de las características microscópicas se tomaron tres acículas maduras de distintos individuos, de las que se cortaron de la parte media trozos de $0.5 \mathrm{~cm}$ de longitud, mismos que se colocaron en frascos con agua y unas gotas de detergente en el interior de una incubadora a $60{ }^{\circ} \mathrm{C}$ durante 48 horas, para su hidratación. Posteriormente el material se deshidrato e incluyó en parafina de acuerdo con la técnica estándar (Johansen, 1940; Ruzin, 1999; Sandoval, 2005). Se realizaron cortes transversales de $20 \mu \mathrm{m}$ de grosor con un microtomo de rotación marca Leica, modelo RM2125RT, mismos que se desparafinaron, deshidrataron y tiñeron con azul astra-fucsina básica (Kraus et al., 1998). Las fotomicrografías se tomaron con una cámara Canon G9 adaptada a un microscopio Axioskop 40 de Zeiss.

Los caracteres morfológicos descritos son: presencia, color y longitud de la vaina; número de acículas por fascículo; longitud de la hoja, características del margen y número de hileras de estomas abaxiales y adaxiales. Para determinar el color de la vaina se utilizaron las tablas Munsell soil color charts (Munsel Color, 1990). En el caso de las características anatómicas, se midió la parte más ancha de la hoja (ancho) y la distancia entre la base y el ápice del corte (alto), además se describen cada uno de los tejidos. La clasificación de las especies que se siguió fue la propuesta por Gernandt, Geada, Ortiz y Liston (2005). Algunos resultados se incluyen en las tablas 2 y 3 .

\section{Resultados}

A continuación, se presentan los nombres comunes, la distribución, la descripción morfológica y anatómica de la hoja de cada una de las especies en estudio.

\section{Pinus arizonica Engelm.}

Nombres comunes: pino, pino alimonado, pino blanco Distribución geográfica: Sonora, Chihuahua, Coahuila, Nuevo León, Durango, San Luis Potosí

Distribución altitudinal: $2500 \mathrm{~m}$ a $2750 \mathrm{~m}$ snm

Características morfológicas (Tabla 2). Fascículos rodeados por una vaina persistente de color castaño que mide de $8 \mathrm{~mm}$ a $9 \mathrm{~mm}$ de longitud, con 3 hojas aciculares de forma triangular, flexibles, de $12 \mathrm{~cm}$ a $13 \mathrm{~cm}$ de longitud, de márgenes aserrados, con 7 a 8 hileras de estomas en la cara adaxial y 8 a 9 hileras en la cara abaxial.

Tabla 2. Características morfológicas de las especies de Pinus estudiadas.

\begin{tabular}{|c|c|c|c|c|c|}
\hline \multirow[t]{2}{*}{ Especies } & \multirow[t]{2}{*}{ longitud de la vaina ( $\mathrm{mm}$ ) } & \multicolumn{2}{|c|}{ acículas } & \multicolumn{2}{|c|}{ hileras de estomas } \\
\hline & & No./fascículo & longitud $(\mathrm{cm})$ & adaxiales & abaxiales \\
\hline \multicolumn{6}{|c|}{ Subsección Ponderosae } \\
\hline P. arizonica & 8 a 9 & 3 & 12 a 13 & 7 a 8 & 8 a 9 \\
\hline P. cooperi & 8 a 12 & 5 & 8 a 10 & 8 a 10 & 8 \\
\hline P. durangensis & 20 a 25 & 5 a 6 & 20 a 22 & 6 & 3 a 4 \\
\hline \multicolumn{6}{|c|}{ Subsección Australes } \\
\hline P. herrerae & 10 a 12 & 3 & 9 a 10 & 6 & 4 \\
\hline P. leiophylla & 15 a 18 & 5 & 9 a 11 & 8 & 5 \\
\hline P. teocote & 5 a 9 & 3 & 7 a 10 & 8 & 5 \\
\hline
\end{tabular}

Tabla 3. Características microscópicas de las especies de Pinus estudiadas

\begin{tabular}{lccccc}
\hline \multirow{2}{*}{ Especies } & \multicolumn{2}{c}{ Acículas } & \multicolumn{3}{c}{ Canales resiniferos } \\
\cline { 2 - 6 } & altura & anchura & número & posición & no. de células epiteliales \\
\hline P. arizonica & 630 & 950 & 2 & media abaxial & 5 a 10 \\
P. cooperi & 884 & 1140 & 5 & media abaxial & 7 a 9 \\
P. durangensis & 855 & 760 & 3 & media 2 abaxiales 1 adaxial & 8 a 9 \\
P. herrerae & 542 & 874 & 1 & interna abaxial & 8 a 9 \\
P. leiophylla & 618 & 760 & 5 & media 4 abaxiales 1 adaxial & 4 a 9 \\
P. teocote & 475 & 855 & 1 & interna abaxial & 10 \\
\hline
\end{tabular}


Características microscópicas (Figs: 1a; 2a; Tabla 3). En sección transversal la hoja presenta forma triangular, de 630 $\mu \mathrm{m}$ de alto y $950 \mu \mathrm{m}$ de ancho. Epidermis uniestratificada con células redondeadas a ovaladas, cubiertas por una cutícula de $2 \mu \mathrm{m}$ de grosor en los lados y $3 \mu \mathrm{m}$ en los ángulos; aserrada; estomas presentes en la superficie adaxial y abaxial, hundidos. Hipodermis, formada por dos hileras de fibras de esclerénquima en las caras rectas y de tres a cuatro en los ángulos, está ausente a la altura de las células oclusivas de los estomas, las cuales quedan en contacto con el mesófilo. Mesófilo homogéneo, consta de dos hileras de células de parénquima clorofílico que se incrementan a tres en los ángulos, sus paredes forman pliegues o crestas, dando el aspecto característico al tejido; se presentan dos canales resiníferos que se localizan en posición media, hacia los ángulos de la cara abaxial, están compuestos de cinco a 10 células epiteliales. Un estrato de endodermis rodea al sistema vascular, el cual está formado por dos haces vasculares colaterales en posición central, con el xilema hacia la cara adaxial y el floema hacia la abaxial, separados entre sí por células de parénquima. Entre la endodermis y los haces vasculares se presenta el tejido de transfusión formado por traqueidas y parénquima.

\section{Pinus cooperi C. E. Blanco}

Nombres comunes: albacarrote, balcarrote, ocote, pino amarillo, pino chino

Distribución geográfica: Chihuahua, Durango, Nayarit

Distribución altitud: $2400 \mathrm{~m}$ a $2727 \mathrm{~m}$ snm

Características morfológicas (Fig: 2b; Tabla 2). Fascículos rodeados por una vaina persistente de color castaño oscuro que mide $8 \mathrm{~mm}$ a $12 \mathrm{~mm}$ de longitud; con 5 hojas aciculares de forma triangular, rígidas, de $8 \mathrm{~cm}$ a 10 $\mathrm{cm}$ de longitud, con los márgenes aserrados, con 8 a 10 hileras de estomas en la cara adaxial y 8 hileras de estomas en la cara abaxial.

Características microscópicas (Figs: 1b; 2c; Tabla 3). En sección transversal la hoja presenta forma triangular, de 884 $\mu \mathrm{m}$ de alto y $1140 \mu \mathrm{m}$ de ancho. Epidermis uniestratificada con células redondeadas, cubierta con una cutícula de $1 \mu \mathrm{m}$ de grosor en los lados y $2 \mu \mathrm{m}$ en los ángulos; estomas presentes tanto en la superficie adaxial como la abaxial, hundidos. Hipodermis formada por una hilera de fibras de esclerénquima en las caras laterales y de dos a tres en la cara abaxial y en los ángulos, está ausente a la altura de las células oclusivas de los estomas, las cuales quedan en contacto con el mesófilo. Mesófilo homogéneo, consta de dos hileras de células de parénquima clorofilico en las caras laterales, tres en la cara abaxial y se incrementan a cinco en los ángulos, sus paredes forman pliegues o crestas, dando el aspecto característico al tejido; se presentan cinco canales resiníferos en posición media que se localizan sobre la cara abaxial y están compuestos por 7 a 9 células epiteliales. Un estrato de endodermis, rodea al sistema vascular, el cual está formado por dos haces vasculares en posición central, con el xilema hacia la cara adaxial y el floema hacia la cara abaxial, separados por células de parénquima y rodeados por dos hileras de fibras perivasculares. Entre la endodermis y los haces vasculares se presenta el tejido de transfusión formado por traqueidas y parénquima.

\section{Pinus durangensis Martínez}

Nombres comunes: ocote, pino alazán, pino blanco, pino real de seis hojas

Distribución geográfica: Chihuahua, Coahuila, Nuevo León, Durango, Aguascalientes, Jalisco, Michoacán, Guerrero.

Distribución altitudinal: $2400 \mathrm{~m}$ a $3200 \mathrm{~m} \mathrm{snm}$

Características morfológicas (Fig: 2d; Tabla 2). Fascículos rodeados por una vaina persistente de color castaño oscuro que mide de $20 \mathrm{~mm}$ a $25 \mathrm{~mm}$ de longitud, con 5 a 6 hojas aciculares, de forma triangular, flexibles, de $20 \mathrm{~cm}$ a $22 \mathrm{~cm}$ de longitud y los márgenes aserrados, con 6 hileras de estomas en la cara adaxial y de 3 a 4 hileras en la cara abaxial. 


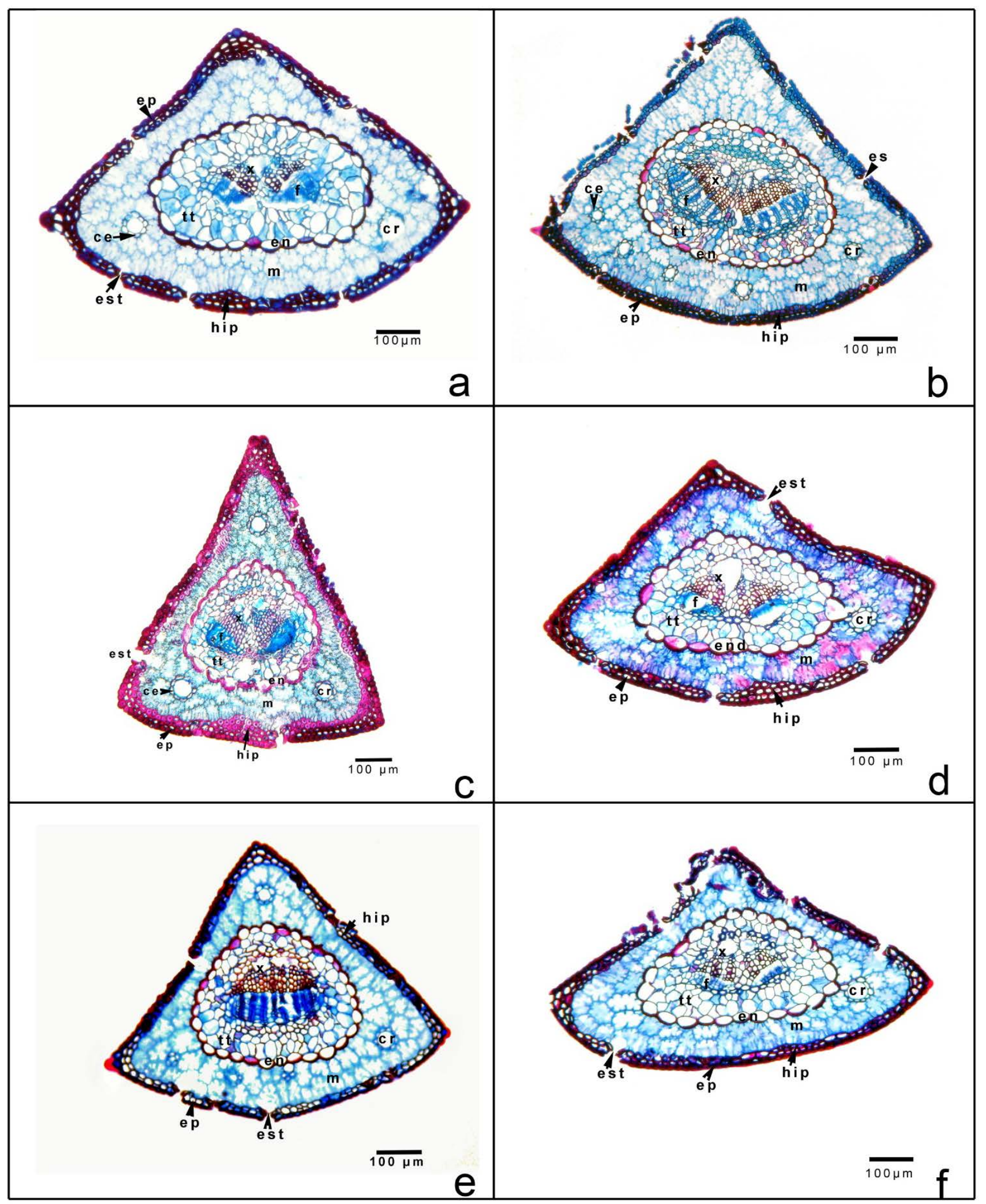

Figura 1. Características microscópicas. Sección transversal de: a) Pinus arizonica; b) P. cooperi; c) P. durangensis; d) P. herrerae; e) P. leiophyla; f) P. teocote.

ep = epidermis, hip = hipodermis, est = estoma, $m$ = mesófilo, $c r$ = canal resinífero, $c e=$ células epiteliales, end = endodermis, tt = tejido de transfusión, $x=$ xilema, $\mathrm{f}=$ floema . 


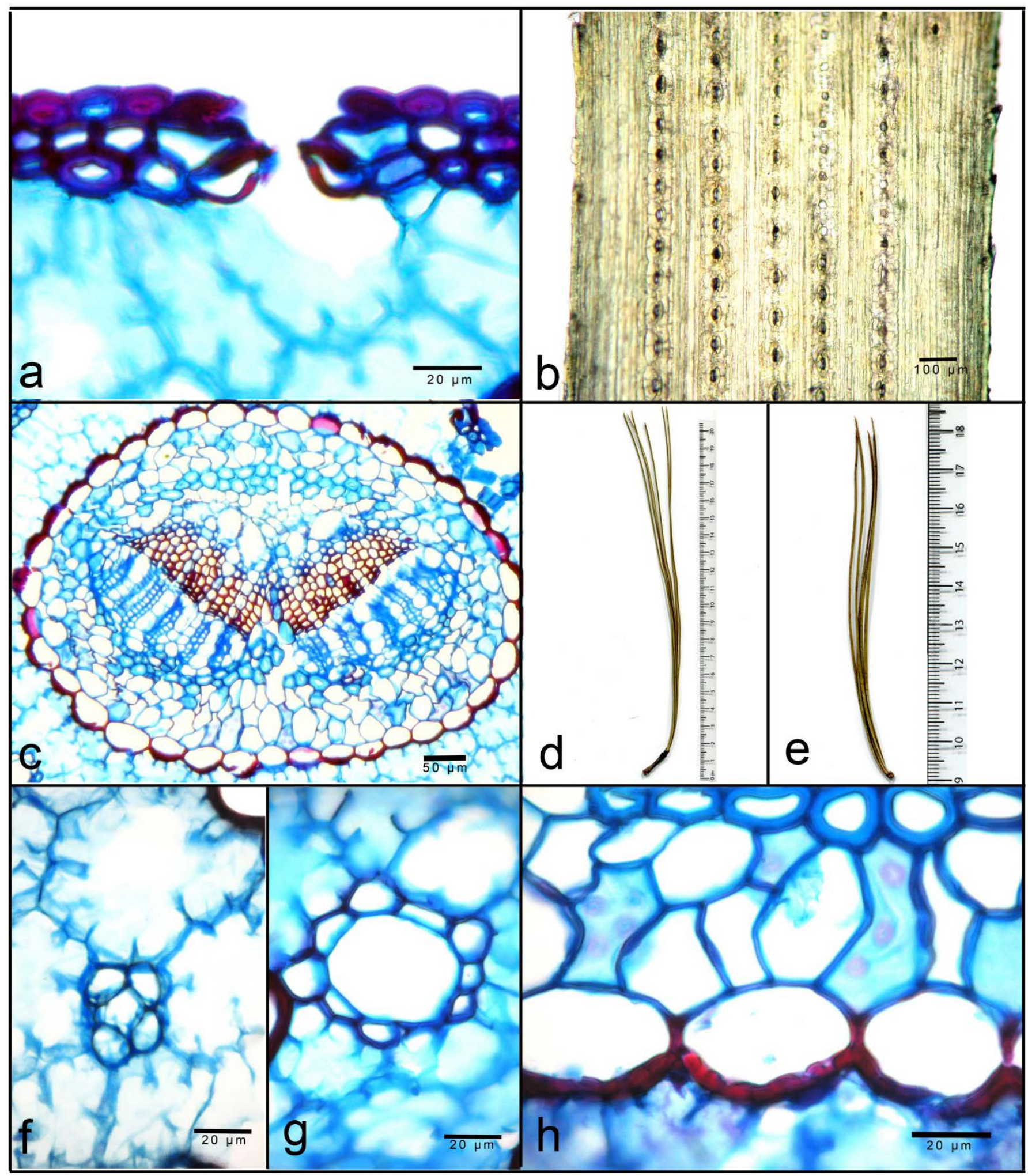

FIGURA 2. Características morfológicas y microscópicass. a) sección transversal mostrando epidermis, hipodermis, estoma y mesófilo, $P$. arizonica; b) estomas y margen en vista superficial, P. cooperi; c) endodermis y sistema vascular, P.cooperi; d) fascículo con vaina persistente, $P$. durangensis; e) fascículo con vaina decidua, $P$. leiophyla; f) canal resinífero y mesófilo, $P$. leiophyla; g) canal resinífero y mesófilo, $P$. teocote; h) endodermis y tejido de transfusión, $P$. teocote. 
Características microscópicas (Fig. 1c; Tabla 3). En sección transversal la hoja presenta forma triangular, de 855 $\mu \mathrm{m}$ de alto y $760 \mu \mathrm{m}$ de ancho. Epidermis uniestratificada con células redondeadas, cubierta con una cutícula de $2 \mu \mathrm{m}$ de grosor en los lados y $3 \mu \mathrm{m}$ en los ángulos, estomas presentes tanto en la superficie adaxial como en la abaxial, hundidos. Hipodermis formada por 3 hileras de fibras de esclerénquima en las caras laterales, por 4 en los ángulos de la cara abaxial, y 5 en el ángulo de la adaxial y 5 en la parte media de la cara abaxial, está ausente a la altura de las células oclusivas de los estomas, las cuales quedan en contacto con el mesófilo. Mesófilo homogéneo, consta de 1 hilera de células de parénquima clorofílico en las caras laterales y 2 en la cara abaxial, 3 en los ángulos de la cara abaxial y 5 en el ángulo de la cara adaxial, sus paredes forman pliegues o crestas, dando el aspecto característico al tejido. Se presentan 3 canales resiníferos en posición media, 2 se localizan cerca de los ángulos de la cara abaxial y 1 sobre el ángulo de la cara adaxial, están compuestos por 8 a 9 células epiteliales. Un estrato de endodermis rodea al sistema vascular, el cual está formado por 2 haces vasculares en posición central, con el xilema hacia la cara adaxial y el floema hacia la cara abaxial, separados entre sí por células de parénquima y rodeados por una hilera de fibras perivasculares. Entre la endodermis y los haces vasculares se presenta el tejido de transfusión formado por traqueidas y parénquima.

\section{Pinus herrerae Martínez}

Nombres comunes: ocote, pino chino

Distribución geográfica: Sonora, Chihuahua, Sinaloa, Durango, Jalisco, Michoacán, Guerrero

Distribución altitudinal: $1800 \mathrm{~m}$ a $2610 \mathrm{~m}$ snm

Características morfológicas (Tabla 2). Fascículos rodeados por una vaina persistente de color castaño claro que mide de $10 \mathrm{~mm}$ a $12 \mathrm{~mm}$ de longitud, con 3 hojas aciculares, de forma triangular, flexibles, de $9 \mathrm{~cm}$ a $10 \mathrm{~cm}$ de longitud y los márgenes aserrados, con 6 hileras de estomas en la cara adaxial y 4 hileras en la cara abaxial.
Características microscópicas (Fig. 1d; Tabla 3). En sección transversal la hoja presenta forma triangular, de 542 $\mu \mathrm{m}$ de alto y $874 \mu \mathrm{m}$ de ancho. Epidermis uniestratificada con células redondeadas, cubierta con una cutícula de $1 \mu \mathrm{m}$ de grosor en los lados y $3 \mu \mathrm{m}$ en los ángulos; estomas presentes tanto en la superficie adaxial como en la abaxial, hundidos. Hipodermis formada por 2 hileras de fibras de esclerénquima y 3 en la parte media de la cara abaxial, está ausente a la altura de las células oclusivas de los estomas las cuales quedan en contacto con el mesófilo. Mesófilo homogéneo, consta de 2 hileras de células de parénquima clorofílico y 3 en los ángulos de la cara abaxial, sus paredes forman pliegues o crestas, dando el aspecto característico del tejido. Se presenta 1 canal resinífero en posición interna en la cara abaxial, está compuesto por 8 a 9 células epiteliales. Un estrato de endodermis rodea al sistema vascular, el cual está formado por dos haces vasculares en posición central, con el xilema hacia la cara adaxial y el floema hacia la cara abaxial, separados por células de parénquima, presentan una hilera de fibras abajo del floema y unas cuantas fibras aisladas por arriba del xilema. Entre la endodermis y los haces vasculares se presenta el tejido de transfusión formado por traqueidas y parénquima.

\section{Pinus leiophylla Schiede ex Schltdl. \& Cham.}

Nombres comunes: ocote, pino chino, pino prieto

Distribución geográfica: Zacatecas, Jalisco, Michoacán, México, Tlaxcala, Distrito Federal, Morelos, Oaxaca, Veracruz

Distribución altitudinal: $2500 \mathrm{~m}$ a $2800 \mathrm{~m}$ snm

Características morfológicas (Fig. 2e; Tabla 2). Fascículos rodeados por una vaina caediza de color castaño claro que mide de $15 \mathrm{~mm}$ a $18 \mathrm{~mm}$ de longitud, con 5 hojas aciculares, de forma triangular, flexibles, de $9 \mathrm{~cm}$ a $11 \mathrm{~cm}$ de longitud y márgenes aserrados, con 8 hileras de estomas en la cara adaxial y 5 hileras en la cara abaxial.

Características microscópicas (Figs. 1e; 2f; Tabla 3). En sección transversal la hoja presenta forma triangular, de 618 $\mu \mathrm{m}$ de alto y $760 \mu \mathrm{m}$ de ancho. Epidermis uniestratificada con células redondeadas, cubierta con una cutícula de $2 \mu \mathrm{m}$ 
de grosor en los lados y $3 \mu \mathrm{m}$ en los ángulos, estomas presentes tanto en la superficie adaxial como la abaxial, hundidos. Hipodermis formada por 2 hileras de fibras de esclerénquima, ausente a la altura de las células oclusivas de los estomas, las cuales quedan en contacto con el mesófilo. Mesófilo homogéneo, consta de 2 hileras de células de parénquima clorofílico en las caras laterales y 3 en los ángulos de la cara abaxial, sus paredes forman pliegues o crestas, dando el aspecto característico al tejido. Se presentan 5 canales resiníferos, 3 en posición media y 1 interno en la cara abaxial y 1 en posición media en el ángulo de la cara adaxial, están compuestos por 4 a 9 células epiteliales. Un estrato de endodermis, rodea al sistema vascular, el cual está formado por dos haces vasculares en posición central juntos, aparentando ser uno, con el xilema hacia la cara adaxial y el floema hacia la cara abaxial, rodeados por una hilera de fibras perivasculares. Entre la endodermis y los haces vasculares se presenta el tejido de transfusión formado por traqueidas y parénquima.

\section{Pinus teocote Schiede ex Schltdl. \& Cham.}

Nombres comunes: albacarrote, balcarrote, ocote, pino amarillo, pino colorado, pino chino, pino prieto, pino rosillo

Distribución geográfica: Chihuahua, Nuevo León, Durango, Zacatecas, San Luis Potosí, Querétaro, Hidalgo, Tlaxcala, México, Distrito Federal, Guerrero, Oaxaca, Chiapas, Veracruz

Distribución altitudinal: 2400 m a 3200 m snm

Características morfológicas (Tabla 2). Fascículos rodeados por una vaina de color castaño oscuro que mide de $5 \mathrm{~mm}$ a $9 \mathrm{~mm}$ de longitud, con 3 hojas aciculares, de forma triangular, flexibles, de $7 \mathrm{~cm}$ a $10 \mathrm{~cm}$ de longitud y los márgenes aserrados, con 8 hileras de estomas en la cara adaxial y 5 hileras en la cara abaxial.

Características microscópicas (Figs. 1f; 2g; 2h; Tabla 3). En sección transversal la hoja presenta forma triangular, de $475 \mu \mathrm{m}$ de altura y $855 \mu \mathrm{m}$ de anchura. Epidermis uniestratificada con células redondeadas, cubierta con una cutícula de $1 \mu \mathrm{m}$ de grosor en los lados y $2 \mu \mathrm{m}$ en los ángulos, estomas presentes tanto en la superficie adaxial como la abaxial, hundidos. Hipodermis formada por 2 hileras de fibras de esclerénquima, está ausente a la altura de las células oclusivas de los estomas, las cuales quedan en contacto con el mesófilo. Mesófilo homogéneo, consta de 2 hileras de células de parénquima clorofílico en las caras laterales y 3 en los ángulos de la cara abaxial, sus paredes forman pliegues o crestas, dando el aspecto característico al tejido. Se presenta 1 canal resinífero en posición interna en la cara abaxial, está compuesto por 10 células epiteliales. Un estrato de endodermis, rodea al sistema vascular, el cual está formado por dos haces vasculares en posición central, con el xilema hacia la cara adaxial y el floema hacia la cara abaxial rodeados por una hilera de fibras perivasculares, separados por células de parénquima. Entre la endodermis y los haces vasculares se presenta el tejido de transfusión formado por traqueidas y parénquima.

\section{DISCUSIÓN}

Entre las características morfológicas que más se destacan de las hojas de los pinos está su forma delgada y larga (acicular), que permite que su relación superficie/volumen sea baja, lo que se considera un carácter xeromórfico (Esau, 1972; Foster y Gifford, 1974; Bold, et al., 1980). Las acículas se presentan en grupos (fascículos) de número variable (Tabla 2), dispuestos de manera helicoidal sobre las ramas, rodeadas en la base por una vaina, en la sección Trifoliae del subgénero Pinus, a la que pertenecen las especies en estudio, se ha registrado que la vaina es persistente (Fig. 2d), excepto en P. lumboltrii y P. leiophyla, (Gernandt et al., 2005), esta última especie se describe en el presente trabajo y se confirma que en la etapa adulta el fascículo carece de vaina (Fig. 2e).

Se ha registrado que en sección transversal la forma de la hoja de los pinos puede ser circular, triangular u ovalada (semicircular), esta característica se ha relacionado con el número de acículas por fascículo, habiéndose observado que a mayor cantidad la forma es más angular (Ghimire et al., 2015). La lámina de las seis especies estudiadas presenta forma triangular (Figs. 1a-f), pero la abertura de los ángulos varía, los más cerrados los presentan $P$. cooperi, $P$. durangensis 
y $P$. leiophylla y los más abiertos $P$. arizonica, $P$. herrerae y $P$. teocote, si consideramos que las tres primeras especies presentan más acículas por fascículo (Tabla 2), se corrobora la relación propuesta.También se presentan diferencias, en el ancho y alto de la sección de la hoja (Tabla 3), el mayor valor en alto y ancho lo presenta $P$. cooperi, la menor altura $P$. teocote y la menor anchura $P$. durangensis y $P$. leiophylla. La forma de la base de la lámina es recta en $P$. durangensis y curvada en las otras cinco (Fig. 1).

En vista superficial las acículas presentan estomas ordenados en hileras tanto en la cara adaxial (haz) como abaxial (envés), así como los bordes aserrados (Fig. 2b), En sección transversal la epidermis está formada por un solo estrato de células con paredes gruesas y lignificadas, cutícula gruesa y estomas hundidos (Fig. 2a), estas características se asocian con estrategias de resistencia al déficit hídrico (Vilela y Acosta, 2001). Adicionalmente, por debajo se localiza una hipodermis pluriestratificada, también de paredes gruesas y lignificadas, interrumpida únicamente por las células oclusivas, la cual proporciona soporte mecánico adicional a la lámina (Fig. 2a).

El mesófilo ocupa la mayor parte del área de la hoja, sus paredes onduladas son características de los pinos (Figs. 1a-f; 2a, c, f-g) y para las que se han propuesto diversas funciones, entre ellas la de aumentar la superficie de aireación y fotosintética (Wiebe y Al-Saadi, 1976).

La función de los canales resiníferos no está claramente comprendida, pero de manera general se consideran que son estructuras que protegen a la planta de ataques de patógenos, como virus y bacterias (Beck, 2010), se ha visto que pueden variar en número y posición en el mesófilo, así como en la cantidad de células epiteliales que los conforman, por lo que se considera pueden proporcionar información útil para la clasificación de las Pinaceae (Ghimire, Kim, Lee y Heo, 2014). Burzo et al. (2004), identificaron tres tipos de canales de acuerdo con su posición: externos, en contacto con la hipodermis; medios, rodeados por clorénquima; e internos, pegados a la endodermis. En este caso P. arizonica y P. cooperi tienen solo canales medios abaxiales, mientras que $P$. durangensis y $P$. leiophylla, presentan abaxiales y adaxiales; y Pinus herrerae y $P$. teocote, poseen sólo canales internos. En cuanto al número, $P$. arizonica tiene $\operatorname{dos} P$. cooperi cinco, $P$. herrerae y $P$. teocote uno, $P$. durangensis tres y P. leiophylla cinco (Figs. 1a-f; Tabla 3). El número de células epiteliales varía de 4 a 10 (Figs. 2fg; Tabla 3).

Entre el mesófilo y el cilindro vascular se localiza la endodermis, tejido de paredes gruesas en el que se observan las bandas de Caspary, cuya función es regular el paso de sustancias (Figs. 1a-f; 2gc-2h). El sistema vascular en el caso de los representantes del subgénero Pinus, se caracteriza por la presencia de dos haces colaterales centrales (Figs. 1a-f; 2c). En cinco especies son muy claros, pero en P. leiophylla parecería que hay solo uno, sin embargo algunos trabajos han reportado que en hojas cotiledonarias y primarias hay un solo haz, pero que en las maduras se distinguen dos (Sheue et al., 2014; Dörken y Stützel, 2012), por lo que este podría ser el caso.

Hacia ambos lados de los haces vasculares se presenta el tejido de transfusión, integrado por parénquima y traqueidas de transfusión (Figs. 1a-f; 2g-h), cuya función se asocia con el almacenamiento de agua y material de reserva (Canny, 1993).

Finalmente cabe mencionar que no se aprecian diferencias anatómicas entre los representantes de las subsecciones Ponderosae y Australes, que pudieran tener utilidad taxonómica.

\section{CONCLUSIONES}

1. Los caracteres morfológicos que variaron entre especies son: el número de acículas por fascículo, longitud de la hoja, vaina persistente o decidua y número de hileras de estomas.

2. P. leiophylla es la única especie con la vaina decidua.

3. En corte transversal, los caracteres que variaron entre los taxa son: abertura de los ángulos de la hoja, forma de la base, alto y ancho de las acículas, número y posición de los canales resiníferos. 


\section{RECONOCIMIENTOS}

Los especímenes empleados en este estudio se recolectaron como parte del Proyecto de investigación Fondo Mixto Conafor-Conacyt 032697: “Caracterización tecnológica de las especies de pino y encino con valor comercial del estado de Durango" que fue financiado en parte por la Conafor-Conacyt. Este proyecto se realizó de manera conjunta con la Asociación de Industriales del Estado de Durango, A.C. (Aifdac). Las autoras agradecen al M. en C. Abel García Arévalo del Instituto de Ecología A. C. Centro Regional Durango, quien encabezó la recolección de los árboles y la identificación de las especies.

\section{REFERENCIAS}

Beck, C. (2010). An introduction to plant structure and development: plant anatomy for the twenty-first century. Cambridge: Cambridge University Press.

Bold, H. C., Alexopoulus, J., \& Delevoryas, T. (1980). Morphology of plants and fungi. Nueva York: Harper and Row.

Burzo, I., Toma, I., Mihăescu, D. E., \& Toma, C. (2004). Comparative study of the secretory structures and volatile oils in some Pinus species. Biologie vegetală, 50, 5-12.

Canny, M. J. (1993). Transfusion tissue of pine needles as a site of retrieval of solutes from the transpiration stream. New Phytologist, 123, 227-232. doi: 10.1111/j.14698137.1993.tb03730.x

Cevallos F, S. R. S., \& Calvillo C., L. (2012). La bistoria que cuentan las plantas. México: Dirección General de Publicaciones y Fomento Editorial.

De la Paz-Pérez O., C. y Dávalos-Sotelo, R. (2016) Anatomía de la madera de seis especies de Pinus (Pinaceae) del estado de Durango, México. Madera y Bosques, 22 (3), 113-132. doi: $10.21829 /$ myb.2016.2231460

Dörken, V. M., \& Stützel, T. (2012). Morphology, anatomy and vasculature of leaves in Pinus (Pinaceae) and its evolutionary meaning. Flora, 207(1), 57-62. doi: 10.1016/j.flora.2011.10.004

Esau, K. (1972). Anatomía vegetal (2a ed.). Barcelona, España: Omega, S.A.

Foster, A. S., \& Gifford, E. M. (1974). Comparative morphology of vascular plants ( $2 \mathrm{a}$ ed.). San Francisco y Londres: W. H. Freeman and Company.
García A., A., \& González-Elizondo, M. S. (2003). Pináceas de Durango (2a ed.). Xalapa, Veracruz: Instituto de Ecología, A. C-Comisión Nacional Forestal.

Gernandt, D. S., Geada-López, G., Ortiz-García, S., \& Liston, A. (2005). Phylogeny and classification of Pinus. Taxon. 54(1), 29-42. doi: $10.2307 / 25065300$

Gernandt, D. S., \& Pérez-de la Rosa, J. A. (2014). Biodiversidad de Pinophyta (coníferas) en México. Revista Mexicana de Biodiversidad, 85(1): S126-S133. doi: 10.7550/rmb.32195

Ghimire, B., Kim, M., Lee, J. H., \& Heo, K. (2014). Leaf anatomy of Pinus thunbergii Parl. (Pinaceae) collected from different regions of Korea. Taxon 44(2), 91-99. doi: 10.11110/kjpt.2014.44.2.91

Ghimire, B., Lee, C., Yang, J., \& Heo, K. (2015). Comparative leaf anatomy of native and cultivated Pinus (Pinaceae) in Korea: implication for the subgeneric classification. Plant Systematics and Evolution, 301(2), 531-540. doi 10.1007/s00606-014-1090-0

Instituto Nacional de Estadística y Geografía [Inegi] (2014). Anuario estadístico y geográfico del estado de Durango 2014. Recuperado de http://internet.contenidos.inegi.org.mx/contenidos/produ ctos/prod_serv/contenidos/espanol/bvinegi/productos/a nuario_14/702825065386.pdf

Johansen, D. A. (1940). Plant microtechnique. Nueva York y Londres: McGraw-Hill Book Company.

Kraus, J. E., de Sousa, H. C., Rezende, M. H., Castro, N. M., Vecchi, C. \& Luque, R. (1998). Astra blue and basic fuchsin staining of plants materials. Biotechnic \& Histochemistry 73(5), 235-243. doi: 10.3109/10520299809141117

Martínez, M. (1948). Los pinos mexicanos (2a ed.). México: Ediciones Botas.

Munsell Color (1990). Munsell Soil-Color Charts. Grand Rapids, Michigan: Munsell Color.

Raven, P. H., Everty, R. F., \& Eichhorn, S. E. (2004). Biología de las plantas. Barcelona, España: Reverté, S. A.

Ruzin, S. E. (1999). Plant Microtechnique and Microscopy. Oxford, Reino Unido: Oxford University Press.

Rzedowski, J. (1978). Vegetación de México. México: Limusa.

Sandoval Z., E. (2005). Técnicas aplicadas al estudio de la anatomía vegetal. Cuadernos 38. México: Instituto de Biología. Universidad Nacional Autónoma de México.

Sheue, C.R., Chang, H.C., Yang, Y.P., Liu, H.Y., Chesson, P., \& Hsu, F.H. (2014). A new classification of marginal resin ducts improves understanding of hard pine (Pinaceae) 
diversity in Taiwan. Flora: Morphology, Distribution, Functional

Ecology of Plants, 209(8), 414-425. doi: 10.1016/j.flora.2014.06.007

Vilela, A. E., \& Acosta, S. (2001). Pinus chiapensis: Un enfoque ecológico de su anatomía foliar. Polibotanica, 11, 111-120.

Wiebe, H. H., \& Al-Saadi, H. A. (1976). The role of invaginations in armed mesophyll cells of pine needles. New Pbytologist, 77(3), 773-775. doi: 10.1111/j.1469-8137.1976.tb04673.x

Manuscrito recibido el 8 de enero de 2018

Aceptado el 6 de julio de 2018

Publicado el 29 de julio de 2019
Este documento se debe citar como:

De la Paz Pérez O., C., \& Ceja-Romero, J. (2019). Anatomía de la hoja de seis especies de Pinus del estado de Durango, México. Madera y Bosques, 25(1), e2511698. doi: 10.21829/myb.2019.2511698 A.C. se distribuye bajo una Licencia Creative Commons Atribución-NoComercialCompartirlgual 4.0 Internacional. 